\title{
Study on the performance evaluation of construction contract management for large scale construction projects
}

\author{
Hua Liu ${ }^{a}$, Ting Wang ${ }^{b}$ \\ Xi'an University of Architecture and Technology, Xi'an 710000, China \\ aliuhualw@126.com, b522400504@qq.com
}

\begin{abstract}
Keywords: Large-scale Contract management, Contract Management, Performance indicators, Fuzzy Comprehensive Evaluation.
\end{abstract}

\begin{abstract}
Large construction project contract management has more project management interface, involving many types of contracts and uncertain factors. So it needs more professional complete contract management system. However whether the contract management is good or not is largely judged by their performance. Therefore, the article carried out the research which is specific to the domestic large-scale construction projects in recent years, analyzing its main features, proposing the impact of large-scale construction project contract management performance evaluation. Through the case analysis, get the contract management performance evaluation value by fuzzy comprehensive evaluation method.
\end{abstract}

\section{Introduction}

In recent years, with the rapid development of China's economy and the technical progress, all kinds of large-scale construction projects has been at home. Due to the capital of the large construction projects takes up more, the payback period is long, various types of contracts were involved, intertwined, Also there are many problems in the management, such as bidding is not standard, the terms of the contract is unreasonable, not rigorous, contract management system is not sound, etc., so how to manage these contracts is particularly important to the project smoothly.

\section{Positioning and characteristics of large construction projects}

\subsection{Location and divide large construction projects}

According to the requirements and the change of economic development in different historical periods, and the national division standard of large construction projects often change, today national division standards of large construction projects are: 1. According to the total amount of investment. Belongs to industrial productive projects of energy, traffic, the raw material department of engineering project, total investment more than 50 million is large and medium-sized construction projects, other departments or non-industrial projects, a total investment amounting to more than 30 million is large and medium-sized construction projects. 2.) According to the design capacity. In this paper, specific division standard is not detail.

\subsection{The characteristics of large construction projects}

In addition to the characteristics of general projects, the large construction projects has the following main features.

(1) The first is that the total amount of investment is huge, large-scale projects such as nuclear power plants, a total investment can be as high as several billion, even billions of dollars, and as big as the three gorges project investment is up to billions of dollars.

(2) The second is the long construction cycle and capital payback period. A large project construction period is short about two or three years, long about seven or eight years. Due to the long construction cycle, a lot of money is used, the output benefit is not reflected in the short term, so the project contract management is a long and complicated process.

(3) Finally, because the interface of project management, many stakeholders involved and project team are multiple, from the project survey, preliminary design, detailed design, supply 
procurement, construction and installation, acceptance to fully completed involving multiple industries and departments, the relationship between each other is complex and management is so difficult.

\section{Large construction project construction contract management influence the factors of performance analysis}

\subsection{The analysis of bidding stage performance influencing factor}

(1) The compilation of tender documents. A good or bad tender documents will directly affect the success or failure of the tender documents, so a bid documents should not only make answer to all the substantial contents in the bidding documents, and the content is complete, clear, careful choice for words, etc.

(2) The professional quality of bidding staff .The tender documentation mentioned above is very important. Then we put forward requirements for the professional quality of bidding staff. Bidding staff should be able to accurately make the bid documents if time is urgent, should have meticulous and serious quality and the ability to overcome difficulties.

(3)The ability of acquire relevant information. We must have a certain understanding on the surrounding environment, policies and competitors, so as to accurately locate the bidding project, have a rough grasp on tender offer.

\subsection{The analysis of performance influence factor on the contract signing stage}

(1)The quality of contract negotiators. The winning bid on the contract signing stage is an important moment that we strive for the interests with party A in the early stage of the project. So how to negotiate is the top priority. Negotiators must know relevant legal knowledge and certain professional knowledge, a certain knowledge about building economy. Thus, we have the ability to safeguard the interests of the contractor.

(2) The examination of the contract.Approval of the contract is a final check before signing the contract. Whether we can kill some hidden dangers in the bud depends on whether the examination is qualified. Authorized personnel are required to be serious at this stage, have relevant construction of legal knowledge and rich practical experience.

3.3 The analysis of the performance influence factor during the phase of performing the contact.

(1)The assignment of contract management responsibility. The management interface of a large construction project is multiple, and time is long. It is easiest to produce some chaotic management issues, management responsibilities can be divided into linear organization chart for reference, in the form of A for contract management department, B1, B2, B3 said the subordinate units or individuals of contract management department , C11, C12, and C13, C21, C22, C23, C31, C32, C33 said the content or standard of contract management .

(2) The cost, schedule, and quality control. All projects are all required to try to improve quality, reduce the progress in the case of saving the cost. In fact, the main criteria of contract management performance evaluation is the economy, and the standard of behavior performance evaluation is to make better service for the results of performance. That is to say, all can improve the means of economics can be used as a behavior performance evaluation factors.

(3) The innovation of management technology. Innovative construction contract refers to the enterprise contract management personnel in the performance of the contract make itself constantly improve and share of knowledge, continuously learn from the elite in the industry, in order to obtain the competitive ability of itself, keep their own core competitiveness, thus they are much earlier than others to adopt new ideas, new technology, new method to improve the level of their contract management. Contract innovation mainly displays from three aspects: the will of the innovation, innovation action and the results.

(4) Risk control. The investment of large construction project is huge, the construction period is longer. They are facing many uncertain factors. How to do a good job in risk management is the key to a successful project. Contractor should strengthen the contract management, strengthen risk 
awareness. From the contract signing stage contractor will be rigorous, judge for the unpredictable risks. During the phase of performing the contract contractor should always grasp the market dynamics, have clear management objectives, strengthen security management, update information collection in time, and prepare for change.

(5) Variation on contract. There is always some uncertain factors affecting the implementation of the rights and obligations on both sides in the process of project implementation, then you need to change the contract in time, ensure contract performed smoothly. Changes contract is normal for a large project, contractor should actively collect information, be ready to change at any time.

(6) The claim of the contract. Large projects takes up huge capital which may be millions. So completing the claim work is of great significance for the contractor. The claim of the contract is the most direct and effective way to maintain the contractor's own interests. How to do claims directly affect the performance of the project. This requires staff to be familiar with law in terms of the contract, and be able to collect evidence on time, tidy up the claim information.

(7) Information updates and transfers. The interface of large project management is multiple .The department set up diversely and dispersedly, not timely docking work may lead to the loss of manpower. Contract management is a dynamic process, need regulation and update information in time, it is advantageous to the contract performed smoothly.

(8) To establish a contract management database. The development and popularization of the computer makes society enter the era of big data. Contract management is a huge work, establishing a database for contract management save time cost, check information conveniently, have very big effect on the contract changes, claims and risk prevention and control work and so on.

\subsection{The analysis of performance influencing factors for the stage of contact subsequent management}

(1) The archiving of the contract information. The contract management of a large construction project is complex. Experience is precious. We should sort out data, file information in time at the end of the project. It is easy to measure project performance, and it is a good reference for the next project.

(2) Social evaluation. Large construction projects are that the projects generally have a great influence on the society, such as roads and railways, or the reconstruction of an area in the city and so on. All these projects are closely related to the public. The success of a large project depends on primarily whether its social evaluation is positive or positive.

(3) The satisfaction of the enterprise .How to judge the performance of a project depends on the satisfaction of the enterprise. The enterprise has an expected value of each project, whether the economic aspect or technological aspect has reached the expected value of the enterprise, the project is positive in the aspects of performance, which can determine that enterprise's satisfaction and performance is the concept of a supplement with each other.

\section{4. .Large-scale construction project contract management performance evaluation - Fuzzy Comprehensive Evaluation Method}

The performance evaluation index of construction contract management has a strong randomness and fuzziness, the dividing line is difficult to clear. It is not easy to carry out an accurate judgment. In order to quantify, it must use a certain number of methods that can depict fuzziness impact of the construction contract management performance indicators so as to perform a comprehensive evaluation $^{[1]}$.

Fuzzy comprehensive evaluation method is just a kind of fuzzy math tools, considering various factors, and making a comprehensive evaluation method for something [2]. The method is based on the fuzzy membership degree theory, and change the qualitative evaluation into quantitative evaluation. In other words, it is restricted by various factors of things or objects and does overall evaluation by fuzzy mathematics method [3]. At the same time, it can also make the boundary fuzzy not quantitative factors using fussy relation composite theory into quantifying, so it can get to comprehensive evaluation.

(1) Determine the evaluation index 
According to the characteristics of large construction projects, this paper lists some factors that influence the project performance on the basis of the induction of literature and make a questionnaire according to these factors. The questionnaire distributed object mainly construction enterprises. A total of 20 who have rich experience of contract management relevant personage score of the above factors according to importance. Greater influence: 5 points; a great Influence: four points; the general effect: three points; Less influence: two points; Almost no effect: one point. Through statistical averaging method, it is concluded that the factors affect weight, the following table4.1:

\begin{tabular}{|c|c|c|c|c|}
\hline & $\begin{array}{l}\text { Contract management } \\
\text { stage } \\
\end{array}$ & Index layer & Score & Weight \\
\hline \multirow{19}{*}{ 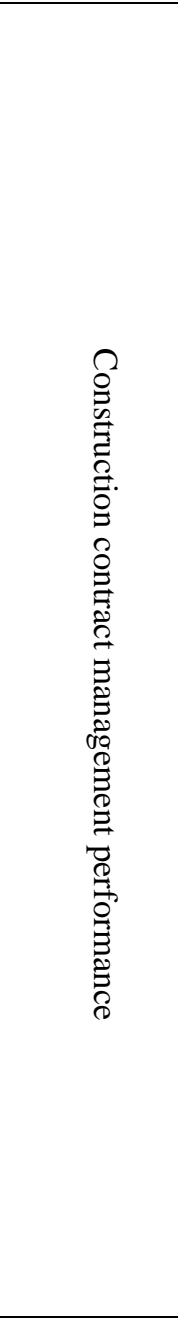 } & \multirow{3}{*}{$\begin{array}{l}\text { The bidding stage } \\
\qquad(0.1088)\end{array}$} & The compilation of tender documents & 3.4 & 0.0514 \\
\hline & & $\begin{array}{l}\text { The professional quality of bidding } \\
\text { staff professional quality }\end{array}$ & 3.8 & 0.0574 \\
\hline & & $\begin{array}{l}\text { The ability of acquire relevant } \\
\text { information }\end{array}$ & 4.1 & 0.0619 \\
\hline & \multirow{3}{*}{$\begin{array}{l}\text { The contract signing } \\
\text { stage } \\
(0.1827)\end{array}$} & The quality of contract negotiators & 2.8 & 0.0423 \\
\hline & & $\begin{array}{c}\text { The terms of the contract } \\
\text { specifications rigour }\end{array}$ & 4.2 & 0.0634 \\
\hline & & $\begin{array}{l}\text { The examination and approval of the } \\
\text { contract }\end{array}$ & 3.6 & 0.0151 \\
\hline & \multirow{9}{*}{$\begin{array}{l}\text { The phase of performing } \\
\text { the contact } \\
(0.5045)\end{array}$} & $\begin{array}{l}\text { The assignment of contract } \\
\text { management responsibility }\end{array}$ & 4.4 & 0.0665 \\
\hline & & Cost, schedule, and quality control & 4.8 & 0.0725 \\
\hline & & $\begin{array}{l}\text { the innovation of management } \\
\text { technology }\end{array}$ & 1.8 & 0.0272 \\
\hline & & Risk control & 3.9 & 0.0589 \\
\hline & & Variation on contract & 4.2 & 0.0634 \\
\hline & & The claim of the contract & 4.8 & 0.0725 \\
\hline & & Information updates and transfers & 3.1 & 0.0468 \\
\hline & & $\begin{array}{l}\text { Establish a contract management } \\
\text { database }\end{array}$ & 2.1 & 0.0317 \\
\hline & & $\begin{array}{l}\text { The supervision and inspection of the } \\
\text { contact }\end{array}$ & 4.3 & 0.0650 \\
\hline & \multirow{4}{*}{$\begin{array}{l}\text { Subsequent contract } \\
\text { management } \\
(0.1646)\end{array}$} & $\begin{array}{l}\text { The archiving of the contract } \\
\text { information }\end{array}$ & 2.8 & 0.0423 \\
\hline & & $\begin{array}{l}\text { The evaluation after the contract } \\
\text { management }\end{array}$ & 2.1 & 0.0317 \\
\hline & & Social evaluation & 1.8 & 0.0272 \\
\hline & & The satisfaction of the enterprise & 4.2 & 0.0634 \\
\hline Total score & & & 66.2 & \\
\hline
\end{tabular}

(2)Fuzzy comprehensive evaluation method step

1) Fuzzy comprehensive evaluation factors identified

Factors sets: $\mathrm{A}=\{\} \mathrm{Bi},(\mathrm{I}=1,2, \ldots \mathrm{n})$, Bi factor is the first of the evaluation index system of the target layer decomposition, is determined by the factors of rule layer, namely the $\mathrm{Ai}=(\mathrm{Bi} 1, \mathrm{Bi} 2, \ldots$, $\mathrm{Bij}),(\mathrm{j}=1,2, \ldots, \mathrm{m})$, and $\mathrm{Bij}$ is determined by the factors of index layer.

2) Determine the fuzzy evaluation matrix $R$

Determine the evaluation set

Evaluation set is given according to the rating criteria for evaluation objects, is set to $R, R=\{R j\}$, $(\mathrm{j}=1,2, \ldots, \mathrm{m})$. Of construction contract management performance evaluation, evaluation criteria can be divided into excellent, good, medium, low, bad five levels, namely $\mathrm{R}=\{\mathrm{R} 1, \mathrm{R} 2, \mathrm{R} 3, \mathrm{R} 4, \mathrm{R} 5\}=$ \{excellent, good, medium,low, bad\}

Determine the index membership degree 
Evaluation of the project construction contract is a kind of fuzzy mapping, different evaluation personnel evaluation index may give different evaluation results for the same, so the result can only be used for the ith a index to make the first $\mathrm{j}$ may be said that the size of the degree of this possibility degree is called a membership.

$\mathrm{Ri}=\{\operatorname{rij}\},(I=1,2, \ldots, \mathrm{n} ; \mathrm{j}=1,2, \ldots, \mathrm{m}) \mathrm{Bij}$ said index for the first $\mathrm{j}$ level evaluation of $\mathrm{Ri}$ membership degree, through the expert evaluation of statistics collected from the value of rij. $\mathrm{I}=1$, $2, \ldots, \mathrm{n}$, are:

$$
\mathrm{r}_{i j}=R_{i j} / \sum_{j=1}^{m} R_{i j} \quad(\mathrm{j}=1,2, \ldots, \mathrm{m})
$$

Therefore, according to the worth of rij vector Ri.

In conclusion, according to the order of the construction contract management performance evaluation index system and the order of the $\mathrm{R}$ rating to determine the membership degree of each index, further fuzzy evaluation matrix:

$$
R_{i}=\left[\begin{array}{l}
R_{1} \\
R_{2} \\
\cdots \\
R_{n}
\end{array}\right]=\left[\begin{array}{cccc}
r_{11} & r_{12} & \cdots & r_{15} \\
r_{21} & r_{22} & \cdots & r_{25} \\
\vdots & \vdots & \vdots & \vdots \\
r_{n 1} & r_{n 2} & \cdots & r_{n 5}
\end{array}\right]
$$

3) Determine the evaluation vector

Single factor comprehensive evaluation

By single factor fuzzy evaluation matrix determine its evaluation vector $\mathrm{Bi}$, its computation formula is as follows:

$$
\mathrm{B}=\mathrm{A} \times R i=\left(\alpha_{11} \alpha_{12} \cdots \alpha_{1 n}\right) \times\left[\begin{array}{cccc}
r_{11} & r_{12} & \cdots & r_{1 m} \\
r_{21} & r_{22} & \cdots & r_{2 m} \\
\vdots & \vdots & \vdots & \vdots \\
r_{n 1} & r_{n 2} & \cdots & r_{n m}
\end{array}\right]=\left(b_{1} b_{2} b_{3} b_{4} b_{5}\right)
$$

Multi-factor comprehensive evaluation

The above results bj comprehensive evaluation matrix $(j=1,2,3,4,5)$ constitute A Ri, using the same method combines $\mathrm{Ri}$ and $\mathrm{A}$, and $\mathrm{Bi}(\mathrm{I}=1,2,3,4,5)$, Bi again by A matrix $\mathrm{R}$, it is concluded that A comprehensive evaluation matrix $\mathrm{B}$, its computation formula is as follows:

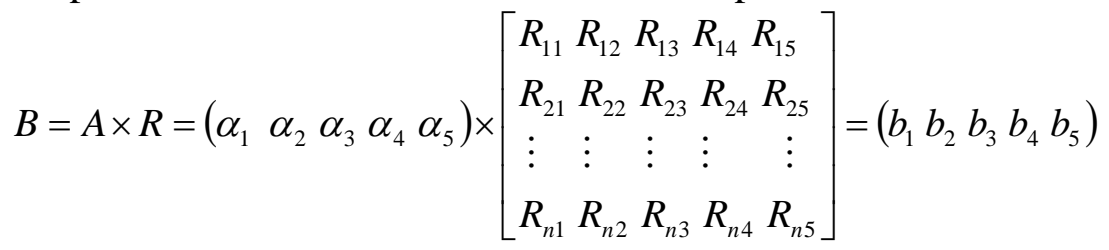

$\mathrm{B}=(\mathrm{b} 1, \mathrm{~b} 2, \mathrm{~b} 3, \mathrm{~b} 4, \mathrm{~b} 5)$ is a set of construction contract management performance of the fuzzy comprehensive evaluation. B to comprehensively consider the effect of the primary and secondary indexes, keep all the information in the evaluation index.

(3) The value of the acquisition

The fuzzy comprehensive evaluation method, through the establishment of fuzzy comprehensive evaluation factor set, determine the fuzzy evaluation matrix and vector, then using the following formula of construction contract management performance value to calculate:

$A=B \times C^{T}$

Wherein, $\mathrm{A}$ is a comprehensive evaluation of the value of construction contract management performance, $\mathrm{B}$ for the comprehensive evaluation vector, $\mathrm{C}$ is the construction contract management performance evaluation grade vector matrix, where $C=\left(\begin{array}{llll}5 & 4 & 3 & 2\end{array}\right.$ 1), corresponding to the rating scale (excellent, good, medium, low, bad).

By fuzzy comprehensive evaluation method, according to the contract management performance evaluation index system and index weight, can be respectively to find the whole process of 
construction contract management performance evaluation and management performance evaluation value in stages.

\section{The example analysis}

A large residential area project covers an area of $751 \mathrm{mu}$, the total surface area of 1.6 million square meters, including houses, villas, apartments and shops, divided into north and south two plots, phase I and phase ii, a total of 31 house, 3 period has not yet finish, the large project investment, long construction period, the contract management is difficult.

In accordance with the above model, we in the project construction contract management performance evaluation.

To determine the index weight

Invited five experts involved in the project construction contract for the performance of the primary indicators and secondary indicators.

1) The weights are level

We according to the experts of various indicators, calculated $(\mathrm{A} 1)=0.1088$, the bidding stage stage $(\mathrm{A} 2)=0.1827$, the contract signing stage $(\mathrm{A} 3)=0.5045$ of the contract, contract follow-up management $(\mathrm{A} 4)=0.1646$

2) Secondary index weight

We take the primary index in the subsequent contract management (A4) as an example to calculate the weight of the index under secondary index. First of all, according to expert scoring, the fuzzy analytic hierarchy process (ahp) to get the weight vector $\mathrm{A} 4=(0.207,0.0185,0.3991,0.207)$.

Through five experts for the performance of construction contract rated secondary indicators, and then according to the formula (4 - 2) get standardized matrix $\mathrm{R}$

Evaluation vector is obtained by formula (4-3) for $\mathrm{B}=(0.3537,0.1876,0.5179,0.3537)$

The last comprehensive evaluation of 4-5 to give the contract management phase is the follow-up by the formula $\mathrm{A}=(0.3537,0.1876,0.4179,0.3383)=2.8253$. It can be seen that the project management contract subsequent general effect.

\section{Conclusion}

This paper puts forward the orientation and characteristics of large construction projects on the basis of comprehensive literature and questionnaire survey finds the contract management performance indicators, and apply to the use of subjective and objective analysis method and fuzzy comprehensive evaluation method to evaluate a project contract management performance, As a result, it provides the basis for construction enterprises in the later contract management.

\section{Acknowledgement}

This work is supported by analysis and countermeasure research on contract management of large scale construction projects in Shaanxi Province.Item number: 43523106-X - 2013KRM43 / 01. Support channels: Shaanxi Province Soft Science.

\section{References}

[1]Wenming Shao. Performance Evaluation of Green Supply Chain Management Research [D] Shanghai: Tongji University, 2008.

[2]Gao Jiang. Fuzzy Comprehensive Evaluation and Its Application [D] Tianjin: Tianjin University, 2005.

[3]Muzi Chen.Chongqing Liangjiang New Area Logistics Development Evaluation [D] Chongqing: Chongqing Jiaotong University, 2014, 04. 